with the laryngoscope than anyone else, carry out this examination satisfactorily provided that they do not compete with the slanting rays of the sun shining down the barrel of the instrument.

Today there is little excuse for forcing an anaesthetist to work in the dark. Modern fibreoptics provide brilliant illumination during endoscopy, and image intensifiers make radiographic visualization clear in a reasonably lit department. Dr. Lee makes out a good case for anaesthetists refusing to work in complete darkness; their job is often difficult enough in the light.

\section{Actinic Reticuloid}

The dermatoses which affect exposed skin and are made worse by light present formidable diagnostic and therapeutic problems, and these conditions are getting more common. More and more skin is seen in the street every year as the amount of the body covered by clothes is reduced by trends of fashion. At the same time, the range of chemicals, used topically or systemically, which have proved to have photosensitizing properties has also increased.

The adequate investigation (as distinct from the mere confirmation of a diagnosis) of apparent photosensitivity requires elaborate equipment and makes heavy demands on the time of both physician and patient. This limits the numbers of clinical photobiological centres, but this limitation has had the advantage of attracting to these few centres clinical problems from many parts of the country, thus making it possible to define and elucidate syndromes which are relatively rare.

Dr. Magnus and his colleagues at the Institute of Dermatology in London" have recently characterized as "actinic reticuloid" a syndrome which most dermatologists have probably encountered and will remember as a source of therapeutic frustration. The patients described were 10 elderly men with a chronic eczematous eruption predominantly affecting the exposed skin of the face, hands, and forearms, but often affecting also the relatively shaded areas of the neck and extending to contiguous covered skin on the arms and elsewhere. Most patients had episodes in which there was almost universal erythroderma. In long-standing or severe cases oedematous plaques produced gross furrowing and distortion of the features, and lichenoid papules and plaques often added a further distinctive feature.

The eruption cleared slowly when the patients were confined to an almost completely darkened room and relapsed rapidly on re-exposure to daylight. Most patients were not aware that the condition was made worse by light, partly because there was no obvious seasonal fluctuation in its severity, partly because exposure to daylight, as distinct from full sunlight, was sufficient to provoke or perpetuate it, and partly because in some cases fluorescent tube lighting could also induce relapses. The condition proved resistant to many forms of treatment-chloroquine and methotrexate systemically and steroids, sunscreening creams, and grenz-rays topic-

\footnotetext{
1 Ive, F. A., Magnus, I. A., Warin, R. P., and Jones, E. W., British fournal of Dermatology, 1969, 81, 469.

- Brown, S., Lane, P. R., and Magnus, I. A., British Fournal of Dermatology, 1969, 81, 420.

3 Crow, K. D., Wilkinson, D. S., and Osmundsen, P. E., British fournal of Dermatology, 1969, 81, 180 .
}

ally-and was so incapacitating that many of the patients developed reactive depression and no fewer than five had attempted suicide.

The histological changes in the affected skin were remarkable. The density and character of the cellular infiltrate suggested a reticulosis with features resembling Hodgkin's disease or mycosis fungoides, but though abnormal lymphoid cells were numerous mitotic figures were rare, and though there were many giant cells none of the characteristic Hodgkin's type were found. Nevertheless the simulation of a reticulosis was sufficiently close to cause real anxiety and would confound the inexperienced or unwary.

The quantitative asessment of the photosensitivity of these patients also gave results which were interesting and unusual. The patients produced an erythematous and oedematous response to small doses of the sunburn wavelengths but also a morphologically abnormal response with long-wave ultraviolet light and even with visible light. The sensitivity to long ultraviolet wavelengths explains the exacerbations that some patients rightly attributed to fluorescent lighting. ${ }^{2}$

This syndrome is sufficiently distinctive to be readily identifiable in all but its earliest stages. The early or mild case must be differentiated from photocontact dermatitis, such as may be induced by the halogenated salicylanilides in soaps ${ }^{3}$ and from certain forms of simple allergic contact dermatitis, notably that caused by chrysanthemums and some botanically related plants. However, all such dermatoses fluctuate in severity in relation to the seasonal occurrence of the allergen or of sufficiently bright sunshine. Actinic reticuloid is remorselessly persistent unless the patient lives in almost total darkness.

The cause and nature of actinic reticuloid are unknown. The remission of symptoms which consistently follows avoidance of light makes it improbable that the syndrome is in fact a prereticulosis, but it would be premature to exclude the possibility.

\section{Invasion of Privacy}

One of the acknowledged defects in English law is the lack of any redress for invasion of privacy. Nothing can be done to stop a newspaper printing an embarrassing photograph no matter how obtained. "Public interest" is the excuse offered on such occasions; and last week the Press Council followed this convention when it rejected a complaint by the relatives of a patient who had been named by the Daily Telegraph as the recipient of a heart transplant despite their requests for anonymity.

By their code of ethics doctors assure patients that consultation and treatment will be kept confidential. Any patient should be able to be certain that his presence in hospital, his diagnosis, and his treatment will be kept secret if he so wishes. A newspaper can always ferret out the identity of a patient if it tries hard enough, but for it to print the facts-especially when it does so against the expressed wishes of the patient or his close relatives-is an intrusion into the doctor-patient relationship. This must be wrong. The only exception is that of personalities in the public eye whose state of health in general terms is legitimately of public concern. Last week the Press Council betrayed the standards it was set up to advance. 